\title{
O museu como agente de transformação - a inclusão cultural $^{1}$
}

Maria de Fátima F. Faria Gomes ${ }^{2}$, Marcelo Bernardo da Cunha ${ }^{3}$

\section{Apresentação:}

Neste presente trabalho, propomo-nos abordar a inclusão social, um tema bastante delicado, atual e que deve ser analisado através de uma reflexão que nos possibilite galgar caminhos que transponham com mais segurança as dificuldades inerentes ao seu grau de complexidade. Procuraremos analisar como este tema se desenvolveu no Brasil com referência às ações museológicas e às Políticas Culturais implantadas pelo governo em seus três níveis de atuação no país com a finalidade de disseminar e normalizar estas ações em todo o território nacional. A palavra inclusão, no contexto aqui apresentado, refere-se à defesa do direito de todo ser humano de

\footnotetext{
${ }^{1}$ Texto baseado na Dissertação de Mestrado "O museu como Vetor da Inclusão Cultural", tendo como orientador o Prof. Dr. Marcelo Nascimento Bernardo da Cunha, junto à Universidade Lusófona de Humanidades e Tecnologia em 2010 2

${ }^{3}$ Professor no Colegiado de Museologia da Universidade Federal da Bahia- Salvador

${ }^{4}$ O Brasil é uma República Federativa onde o poder executivo atua em 3 níveis de governo: 1- Governo Federal; 2- Governo Estadual; 3- Governo Municipal
} 
participar das mais variadas esferas sociais, culturais e educativas. A necessidade da inclusão indica que existem situações de exclusão a qual é manifestada de diversas maneiras na sociedade.

A nossa reflexão parte de uma visão da inclusão a partir da perspectiva cultural. Uma nação pode ser reconhecida ou se identificar pela sua cultura e apesar de que esta possa ser um campo de tensões, o reconhecimento de sua pluralidade e diversidade permite uma aceitação e uma integração entre as diferenças amenizando consequentemente estes possíveis conflitos.

Neste sentido, o museu e seu patrimônio representativo podem participar e atuar como um importante instrumento de inclusão social, através da inclusão cultural, tendo a cultura como forma de encantamento e de reforço não só dos valores bem como da própria identidade do indivíduo e o museu, como vetor deste processo inclusivo. Portanto é muito importante que não só os museus, mas as demais instituições culturais estejam em perfeita sintonia com o pensamento e as políticas culturais contemporâneas, pois são pensamentos e políticas que não só reconhecem a diversidade cultural e social, como procuram trabalhar em favor da extroversão de seus objetos culturais, sob o aspecto multicultural, contribuindo, desse modo, para a democratização social e cultural por meio de processos de Inclusão Social (Tojal, 2007). O museu como meio, como polo de multiplicação e de inserção, procura, através da troca de um novo olhar com o público, proporcionar experiências positivas que permitam fortalecer a autoestima, além de ter a possibilidade de estimular uma imagem positiva de si mesmo.

Analisando mais detidamente este contexto, observase que o museu tem um papel importante, pois, como ressalta Bruno em seu artigo no Cadernos de Sociomuseologia (1997), p.42: "Os museus, nas últimas 
décadas, têm desempenhado um papel relevante e específico no campo da democratização da cultura, rompendo as barreiras dos seus espaços tradicionais, procurando novos públicos e criando exposições que incorporam linguagens mistas".

Mais especificamente no Brasil, no mesmo artigo, Bruno (1997,p.42) observa:

Os museus brasileiros têm contribuído para melhor compreensão deste universo caleidoscópio que envolve o "meio" e a "raça" deste território e desta nação; serviram em alguns momentos como expressão de um projeto nacional; e tem demonstrado a multiplicidade de formas e cores que está na base dos distintos processos criativos que aproximam e misturam as influências nativas, africanas e europeias.

A indagação que permanece no final desse percurso é saber se os museus, de uma forma geral, se permitiram mudanças reais para se tornarem acessíveis, se conseguiram sair de suas posturas muitas vezes elitistas ao conceberem seus textos e seus percursos expositivos, procurando atingir um público que não partilha dos mesmos códigos conceituais, buscando compreender até que ponto os museus estão prontos para se permitirem essa mudança de abordagem.

Nossas considerações serão baseadas em levantamento e análise da bibliografia produzida sobre o tema proposto, procurando-se acompanhar a evolução de seu percurso principalmente no Brasil no decorrer do último século e as políticas culturais que foram implantadas e desenvolvidas pelas esferas governamentais no Brasil com o aporte da sociedade civil, tendo a finalidade de gerenciar, conduzir e, de certa forma, instrumentalizar estes programas de inclusão cultural. Temos consciência de que este é apenas um recorte que propomos sobre um tema muito mais amplo e complexo, deixando em aberto um canal para posteriores estudos mais aprofundados. 


\section{A mudança e o amadurecimento do papel do museu no século $X X$ :}

O século $X X$ foi marcado por grandes transformações na área cultural, os museus e as políticas culturais precisaram acompanhar essa mudança. Surgiu daí o conceito "Museologia Social», que procura adequar as estruturas museológicas às necessidades da sociedade contemporânea.

Em 1972, ocorre a Mesa Redonda de Santiago do Chile, organizada pelo ICOM, sobre o papel dos museus na América Latina. Os profissionais ali reunidos tomaram consciência da importância dos problemas vividos em todo o continente. Durante essa reunião, que dá ênfase a função social do museu e o caráter global de suas intervenções, começa a tomar forma o Movimento para uma Nova Museologia. Nesta declaração que ficou conhecida como a Declaração de Santiago (1972 UNESCO/ICOM) foi firmada:

Que o museu é uma instituição à serviço da sociedade da qual é parte integrante e que possui em si os elementos que lhe permitem participar na formação da consciência das comunidades que serve; que o museu pode contribuir para levar essas comunidades a agir, situando a sua atividade no quadro histórico que permite esclarecer os problemas atuais.

A Declaração de Santiago em 1972 foi um marco importante para se repensar o papel do museu frente aos novos tempos e necessidades pelas quais as sociedades vinham passando, principalmente na América Latina. 0 homem retirando-se do centro e passando a se relacionar de uma maneira mais ativa e interativa com o universo circundante. O homem social, o museu social, a vida como um todo, fazendo parte do patrimônio a ser resgatado, a ser estudado, a ser transmitido, em suma, a ser vivenciado.

João Paulo Medeiros Constança em seu texto publicado no Cadernos de Sociomuseologia faz uma análise sobre o significado dessa declaração: 
“A UNESCO, em 1972, incumbindo a Mesa Redonda de Santiago do Chile o tema "Papel do museu na América Latina de hoje", e demonstrando uma preocupação de interdisciplinaridade, fazendo reunir especialistas de vários domínios, procura uma avaliação da capacidade dos Museus em se adaptarem aos problemas postos pelo desenvolvimento da cultura social e económica, da América Latina de então. Este espírito iria reflectir-se, não só numa análise profunda do papel dos museus, como viria a traduzir-se num conjunto de recomendações concretas, visando uma mudança de atitudes nos Museus" (Constança, 1993, p.122).

A partir das reflexões surgidas neste encontro, nasceram dois conceitos: a construção do Museu Integral, com o objetivo de "situar o público dentro do seu mundo, para que este tome consciência de sua problemática como homem-indivíduo e homem-social, por meio de uma visão de Patrimônio Global" e a de museu enquanto ação, isto é, enquanto instrumento dinâmico desta mudança social.

Com a Declaração de Santiago, o museu passa a ter um papel importante na educação da comunidade e a ser o seu agente de desenvolvimento, passando a entender que a ação educativa desenvolvida por ele só seria verdadeira se servisse à libertação, ao questionamento e, permitindo, assim, à reflexão (Primo, 1991).

Em 1984 temos a Declaração de Quebec onde são elaborados os "Princípios de base de uma Nova Museologia" reafirmando-se a Função Social do Museu que entre seus objetivos tinha por base integrar e inserir a população em suas ações - "Museologia Ativa". Segundo Moutinho: ${ }^{5}$

\footnotetext{
${ }^{5}$ Moutinho, Mário C. A Declaração de Quebec de 1984. In: ARAúJO, Marcelo M. e BRUNO, M. Cristina O. org. Memória do Pensamento Museológico Contemporâneo. Documentos e Depoimentos. Comitê Brasileiro do ICOM - 1995, p. 26-30
} 
"Tratava-se de refletir e dar continuidade à reflexão de Santiago, mas também e talvez aqui esteja um dos aspectos mais importantes deste Ateliê, organizar o que se sentia ser um movimento simultâneo em numerosos países, mas no qual os diferentes intervenientes encontravam-se, de certa forma, isolados entre si e naturalmente mais ainda face aos poderes instituídos" (Araújo \& Bruno, 1995, p.26).

O caráter social da museologia, em oposição a uma museologia de coleções, e a defesa da interdisciplinaridade, que se opunha aos saberes isolados, eram importantes pontos defendidos pelos participantes do encontro.

Em seguida, a Declaração de Oaxtepec no México, em 1984, veio reforçar o documento de Quebec quanto à nova realidade que se afigurava aos museus: "La participación comunitaria evita las dificultades de comunicación, característica del monólogo museográfico emprendido por el especialista, y recoge las tradiciones y la memoria colectivas, ubicándolas el lado del conocimento científico ${ }^{6} . "$

No documento de Oaxtepec confirma-se que é indispensável uma visão integrada, indissolúvel do Patrimônio, da Comunidade e do Território. O museu, seja o tradicional, seja o proposto pela Nova Museologia, deve ser capaz de proporcionar ao homem confrontar-se com a realidade e, para que esse confronto se realize, é necessário o diálogo e a participação comunitária, evitando-se, por outro lado, o monólogo do técnico especialista.

Em 1985, em Lisboa, Portugal, no II Encontro Internacional de Ecomuseus e Novas Museologias, tivemos a confirmação da Declaração de Quebec e a fundação do Movimento Internacional para uma Nova Museologia MINOM. Seu compromisso era o de fazer do museu um instrumento para a construção da identidade $e$ desenvolvimento com a comunidade, possibilitando e

${ }^{6}$ Declaração de Oaxtepec, México - 1984 
favorecendo o relacionamento cooperativo entre os usuários e profissionais, além da colaboração intercultural.

No primeiro número dos Cadernos de Museologia, Moutinho (1993) ,p.5 em seu texto "Sobre Museologia Social" cita uma declaração de Frederic Mayor, na abertura da XV Conferência Geral do ICOM:

" o fenômeno mais geral do desenvolvimento da consciência cultural - quer se trate da emancipação do interesse do grande público pela cultura como resultado do alargamento dos tempos de lazer, quer se trate da crescente tomada de consciência cultural como reação às ameaças inerentes à aceleração das transformações sociais tem, no plano das instituições, encontrado um acolhimento largamente favorável nos museus.

Esta evolução é evidentemente, tanto qualitativa como quantitativa. A instituição distante, aristocrática, olimpiana, obcecada em apropriar-se dos objetos para fins taxonômicos, tem cada vez mais - e alguns disso se inquietam - dado lugar a uma entidade aberta sobre o meio, consciente da sua relação orgânica com o seu próprio contexto social. A revolução museológica do nosso tempo - que se manifesta pela aparição de museus comunitários, museus 'sans murs', ecomuseus, museus itinerantes ou museus que exploram as possibilidades aparentemente infinitas da comunicação moderna - tem as suas raízes nesta nova tomada de consciência orgânica e filosófica" (Moutinho, 1993, p.5).

Com a Nova Museologia, o sujeito social é uma das principais preocupações, sendo um dos objetivos o envolvimento e consequente desenvolvimento das comunidades sob o ponto de vista cultural, mas também social e por consequência, econômico. Observamos já o prenúncio do sentido do termo "Inclusão Cultural promovendo a Inclusão Social". 
Na XIX Conferência Geral do ICOM em 20017, vemos um aprofundamento e ampliação desse papel, sendo aprovada a seguinte revisão da definição de museu:

"Instituição permanente, sem fins lucrativos, a serviço da sociedade e do seu desenvolvimento, aberta ao público e que adquire, conserva, investiga, difunde e expõe os testemunhos materiais do homem e de seu entorno, para educação e deleite da sociedade".

Dentro dessa nova definição, o museu chamou para si, além de suas funções basilares que são a pesquisa, a preservação e a comunicação do patrimônio cultural, uma responsabilidade social ao se colocar frontalmente à disposição da sociedade para que esta pudesse encontrar nele o meio e a possibilidade de se sentir representada. Contribuindo, sob essa perspectiva, para uma igualdade social a partir de ações positivas de inclusão do diferente, permitindo dessa forma que ele se sinta como parte integrante e integrada deste processo e que a relação entre o homem e o objeto museal, dentro do espaço museológico (seja ele qual for), possa ser fruída em toda a sua plenitude e contemplar todos os tipos de público, sem distinções. Pois ao colecionar os objetos com um fim em si mesmo, sem poder construir nada a partir deles e com eles, não permitindo a eles a oportunidade de significar e, se não der ao homem a oportunidade se significá-los, “o museu estará fadado a se encerrar em si mesmo como uma concha, ocultando o tesouro da memória, patrimônio social coletivo"(Chiovatto, p.3)

É importante frisar que os museus através de suas ações museológicas não podem estar voltados para si mesmos como um narciso. Para que a Museologia seja aplicada plenamente, - por meio da interpretação e uso do

\footnotetext{
${ }^{7}$ XIX Conferência Geral do ICOM, em Barcelona, Espanha, de 1o a 6 de julho de 2001
} 
Patrimônio Cultural e possa atingir seus principais objetivos que são o desenvolvimento social e o exercício da cidadania é necessário desenvolver a face educativa da Museologia. Pois, assim como na educação formal, o processo museológico deve ser compreendido como uma ação que transforma e se transforma (Santos, 2001) ${ }^{8}$.

O museu, como vetor desse processo, propõe-se a trabalhar as diferenças para, assim, poder reduzir as desigualdades, usando o patrimônio que tem sob sua guarda como um instrumento de inclusão de um público que até pouco tempo esteve distante de seus propósitos.

Ainda dentro dessa visão e procurando adequar-se a uma conotação mais contemporânea do seu papel:

"Aos museus, bem como a todas as instituições culturais, cabe também estar em sintonia com o pensamento contemporâneo de respeito e reconhecimento da diversidade cultural e social trabalhando a favor não somente da comunicação de seus objetos culturais, sob um ponto de vista multicultural, como também contribuindo para a democratização cultural por meio dos processos de inclusão social" (Tojal, 2008, p.4).

Sendo, também, importante salientar a necessidade de readequação do profissional do museu que deve colocar, no mesmo patamar que as ações técnicas inerentes a sua formação tradicional, as ações sociais. Sem um trabalho consciente e profissional, em especial do núcleo de educação da instituição, que permita o pleno acesso do público a esse patrimônio, a simples implantação no museu

${ }^{8}$ Texto produzido para aula inaugural proferido pela Professora Maria Célia Santos para o Curso de Especialização em Museologia do Museu de Arqueologia e Etnologia da Universidade de São Paulo, na abertura do Simpósio Internacional "Museu e Educação: conceitos e métodos", realizados no período de 20 a 25 de agosto de 2001, no Museu de Arte Moderna de São Paulo 
de um programa de acessibilidade física ou de inclusão cultural, pensando de uma forma mais ampla, não garantem nem uma apreensão dos conteúdos expositivos de qualidade, nem que se tenha atingido de maneira eficaz o objetivo de se tornar realmente acessível. Muitas vezes ao elaborar seus textos explicativos, a instituição parte do princípio de que o visitante dispõe dos conhecimentos ou capacidades necessários para interpretar os conceitos transmitidos.

Numa publicação do Instituto Português de Museus (IPM), a definição de acessibilidade recebe uma conotação mais ampla, numa abordagem que vai além da adequação física do espaço museológico:

"Acessibilidade é aqui entendida num sentido lato. Começa nos aspectos físicos e arquitectónicos acessibilidade do espaço - mas vai muito para além deles, uma vez que toca outras componentes determinantes, que concernem aspectos intelectuais e emocionais, acessibilidade da informação e do acervo" (IPM, 2004, p.17).

É muito importante a mudança de atitude frente ao diverso, frente ao que não é nosso espelho e que, por vezes, nos afasta. Assim sendo, devemos considerar a inclusão social como um processo maior, que precisa envolver a todos, por isso, a importância das políticas culturais em todas as esferas governamentais (federal, estadual e municipal), pois visa à construção de uma nova sociedade mediante a transformação da mentalidade das pessoas. É um processo lento, pois envolve mudanças comportamentais há muito enraizadas em nossa sociedade.

Num país com uma grande diversidade cultural como o Brasil e, ao mesmo tempo, com grandes dificuldades de acesso a esses bens e manifestações pelas camadas menos favorecidas da população, as políticas culturais, quando bem conduzidas e aplicadas, têm condições de proporcionar uma difusão mais eficiente que permita de uma forma democrática essa inclusão. 
Segundo Teixeira Coelho:

“... a política cultural é entendida habitualmente como programa de intervenções realizadas pelo Estado, instituições civis, entidades privadas ou grupos comunitários com o objetivo de satisfazer as necessidades culturais da população e promover o desenvolvimento de suas representações simbólicas. Sob este entendimento imediato, a política cultural apresenta-se assim como o conjunto de iniciativas, tomadas por esses agentes, visando promover a produção, a distribuição e o uso da cultura, a preservação e divulgação do patrimônio histórico e o ordenamento do aparelho burocrático por elas responsável" (Coelho, 2004, p. 293).

Ainda, segundo Coelho, as Políticas Culturais devem ser concebidas de acordo com valores como o nacionalismo, o pluralismo cultural ou a globalização e, de acordo com esses critérios, as Políticas Culturais seguem alguns caminhos pretendidos.

A Política Cultural evolui e se consolida a partir do somatório das ações desenvolvidas pelos segmentos diretamente relacionados ao longo do tempo.

Procurar administrar a cultura, de acordo com diretrizes e interesses específicos, não é um fenômeno social restrito aos nossos tempos, onde usá-la como instrumento da política, com maior ou menor intensidade, não é uma situação incomum. A situação inversa também pode ser constatada, observando-se o uso da política com finalidades culturais. De qualquer modo, sempre encontraremos indícios de que cultura e política caminharam juntas em alguns momentos, resultando na maioria das vezes em atividades dirigidas (Barbato Jr., 2004).

$\mathrm{Na}$ atualidade, com o amadurecimento destes conceitos, essa relação foi sendo delimitada ao campo das Políticas Públicas, que nos diversos países apresentam critérios e intensidade de intervenções diferenciadas de 
acordo com ideologias e interesses políticos.

No Brasil, numa análise de Calabre, o modelo de relação, onde se visualiza uma proposta de democratização da cultura alicerçada na realização de ações de maior alcance junto à população, teve início na década de 1930, que foi um período de grandes transformações urbanísticas, na área social e econômica, na estrutura do Estado, onde o conceito de cidadania passava a ser aplicado às classes trabalhadoras, um dos novos grupos sociais que estavam consolidando-se no cenário nacional. Infelizmente, os projetos, ações ou políticas implantados na área cultural foram marcados pela ínfima continuidade ou total descontinuidade, o que sempre obrigou a implantação de políticas pontuais ou emergenciais (Calabre, 2007).

$\mathrm{Na}$ atualidade o Ministério da Cultura vem realizando uma gestão compartilhada e participativa, dentro dos princípios orientadores do Plano Plurianual. Este plano tem como estratégia de ação a organização e a implementação de programas por desafios - dentro de ideia de transversalidade e de intersetorialidade. Com isso, o MinC $^{9}$ passa a atuar em conjunto, do ponto de vista metodológico, com outros ministérios: da Educação, do Turismo, do Meio Ambiente, do Trabalho, dos Esportes, da Integração Nacional e das Relações Exteriores. Além de outras instituições públicas como as empresas estatais (Silva, 2007).

Sabe-se o quão difícil é articular todas essas medidas, principalmente quando se pretende abarcar um amplo contingente de proposições. Quando uma política cultural tem em sua concepção a definição de que "cultura é tudo" encontra, por certo, dificuldades em captar e aplicar a amplitude que essa definição traz em si em mecanismos eficazes que venham a viabilizar suas ações.

${ }^{9}$ MinC- Ministério da Cultura do Brasil. 
Mas, é importante salientar que embora vejamos certa dificuldade em colocar em prática um plano de tamanha abrangência, também vemos um lado bastante positivo que é o de se colocar em pauta a preocupação com a necessidade de um planejamento na área cultural, com uma abertura a outras instâncias do poder público, dos fomentadores culturais e, principalmente, da sociedade.

Neste sentido, em 2003, foi criada a Secretaria da Identidade e da Diversidade Cultural, ligada ao Ministério da Cultura. Seu objetivo era o de iniciar o diálogo para a construção de uma política pública voltada à diversidade e às minorias existentes e firmar a participação do Estado brasileiro na promoção e proteção da diversidade cultural.

Além do reconhecimento da diversidade cultural e de respeitá-la como parte integrante do patrimônio cultural e da sociedade, o grande desafio é como instituir a pluralidade como princípio e prática de inclusão. Pois em nossa sociedade onde a diversidade é cada vez mais presente é imprescindível garantir a sua coexistência harmoniosa.

Complementando, Barros afirma que:

"Em nossas sociedades cada vez mais diversificadas, torna-se indispensável garantir uma interação harmoniosa entre pessoas e grupos com identidades culturais a um só tempo plurais, variadas e dinâmicas, assim como sua vontade de conviver. As políticas que favoreçam a inclusão e a participação de todos os cidadãos garantem a coesão social, a vitalidade da sociedade civil e a paz" (Barros, 2008, p. 53).

O Estado deve acompanhar como estão sendo utilizados os incentivos fiscais no patrocínio de ações culturais para que não se financie projetos sem continuidade e que não tenham o interesse social como meta principal. Em relação ao Brasil, através da criação de legislação específica, o poder público e órgãos ligados aos setores culturais procuram fiscalizar e aplicar recursos para 
apoiar projetos culturais que concretizem os princípios da Constituição, em especial os dos arts. 215 e $216^{10}$

A importância de se intensificar as políticas culturais relativas aos museus que com seu papel relevante como vetor da inclusão cultural, tem aumentado a sua responsabilidade social no gerenciamento dessas dinâmicas. A implementação da capacitação de seus profissionais, assim como a adequação de seu mobiliário técnico para a preservação do patrimônio e melhoria das condições de acessibilidade a partir do patrocínio público através de empresas estatais, tem sido um grande alento para a adequação desses espaços. É necessário não perder de vista a importância da inclusão de públicos especiais nas ações inclusivas do museu.

Segundo dados do $\mathrm{IBGE}^{11}$, o Censo Demográfico de 2000 demonstra que aproximadamente 24,6 milhões de pessoas no Brasil, ou seja, 14,5\% da população são portadoras de algum tipo de deficiência. É um número bastante expressivo dentro da população global, um público cada vez mais participativo e que tanto o poder público como a sociedade civil precisam estar conscientes de sua inclusão em todas as áreas de atuação humana e aí abrangemos com destaque a área cultural. Projetos desenvolvidos pelos museus não podem ser ações isoladas e estanques, o apoio

10 1- Declaração dos direitos das pessoas com deficiência Resolução aprovada pela Assembléia Geral da ONU em 09/12/75

2- Declaração de Salamanca sobre Princípios, Políticas e Práticas na Área das Necessidades Educativas Especiais-ONU, 1994

3- Convenção sobre a Proteção e Promoção da Diversidade das Expressões Culturais - UNESCO, 2005

11 IBGE- Instituto Brasileiro de Geografia e Estatística - Comunicação Social de 16 de setembro de 2005 - disponível em http://www. ibge.gov.br/home/presidencia/noticias/noticia_impressao.php?id_ noticia $=438$ 
das políticas públicas na área de cultura é fundamental para a sua institucionalização e normalização, garantindo assim o pleno acesso, a vivência e a experiência tão cara e necessária a todos os seres humanos, não importando a raça, a condição social, o credo e as condições físicas ou mentais.

Portanto, é muito importante que os museus e as instituições culturais estejam em perfeita sintonia com o pensamento e as políticas culturais contemporâneas, pois são pensamentos e políticas que não só reconhecem a diversidade cultural e social, como procuram trabalhar em favor tanto da extroversão de seus objetos culturais, sob o aspecto multicultural, contribuindo, desse modo, para a democratização social e cultural por meio de processos de Inclusão Social (Tojal, 2007).

O museu como meio, como polo de multiplicação e de inserção, procura, através da troca de um novo olhar com o público, proporcionar experiências positivas que permitam fortalecer a autoestima, além de ter a possibilidade de estimular uma imagem positiva de si mesmo. Melhorar o atendimento atingindo, além dos objetivos quantitativos, os qualitativos, mostrando uma preocupação com o público no mesmo nível que a de conservar, de restaurar e de estudar os objetos sob sua guarda.

Mas, que papel o museu poderia chamar para si no combate a exclusão social?

Esta é uma pergunta bastante complexa a que os museus têm sido confrontados. E o desenvolvimento de programas socioeducativos permite uma abordagem multidisciplinar por parte dos museus que tem no seu patrimônio cultural ou natural o grande elemento provocador e estimulador da inclusão. Os museus, ao interpretarem como sinônimos a inclusão social e cultural assumem que seu papel vai muito além de preservar o patrimônio, se colocando como agentes ativos nessa 
transformação. Eles podem desempenhar um papel importante na geração das mudanças sociais cooperando e capacitando as pessoas para que elas próprias possam determinar seu lugar no mundo, educarem-se para desenvolverem os seus potenciais, e participarem plenamente na sociedade além de contribuir para transformá-la no futuro (The GLLAM Report, 2000).

Para Aidar:

“Dessa forma, um redimensionamento das práticas museológicas se faz necessário ao se adotar um paradigma mais inclusivo. Em termos ideológicos, as instituições devem mover-se na direção do reconhecimento da ideia de que elas têm um papel a contribuir para a igualdade social, para o fortalecimento de indivíduos e grupos em desvantagem e para o incremento de processos democráticos dentro da sociedade" (Aidar, 2002, p.6).

Neste processo é importante salientar o aprendizado que o museu deve se permitir para melhor se adequar frente às novas empreitadas desafiadoras. A pesquisa, a consulta à comunidade à qual se propõe atingir, a readequação do ambiente e principalmente a sensibilização e capacitação do profissional do museu são fatores importantes para se imprimir um caráter verdadeiro, profissional e humano quando se trata de acessibilidade.

A instituição deve permitir o direito de escolha, por parte do público que ela pretenda que se sinta incluído. 0 fato deste não concordar com os seus critérios e escolhas apresentados de abordagem inclusiva, deve ser visto de uma maneira positiva e estimular, por outro lado, a pesquisa compartilhada de soluções adequadas.

"O direito à escolha tem sido reclamado pelo público frequentador dos museus e é um fator importante para a efetivação de mudanças sensoriais e atitudinais. Da mesma forma, esse público quer opinar quanto ao conteúdo das diretrizes elaboradas pelas políticas culturais das 
instituições, que demandam reestruturações em todas as áreas museológicas, principalmente na área comunicacional. Aliás, a área comunicacional é a que tem por função conceber exposições baseadas no modelo emergente, baseadas em propostas mais interativas com os objetos e com os diferentes níveis de informação sobre os conteúdos nelas apresentados, ao levar em consideração os diversos graus de compreensão e de diversidade dos públicos visitantes" (Tojal, 2007, p.178).

\section{Conclusão:}

A indagação que permanece no final desse percurso é saber se os museus, de uma forma geral, se permitiram mudanças reais para se tornarem acessíveis, se conseguiram sair de suas posturas muitas vezes elitistas ao conceberem seus textos e seus percursos expositivos, procurando atingir um público que não partilha dos mesmos códigos conceituais, buscando compreender até que ponto os museus estão prontos para se permitirem essa mudança de abordagem.

Os caminhos trilhados se foram adequados ou não, já foram percorridos, museus foram criados, ações foram normalizadas, permitindo, assim, uma proteção legal através de legislação específica e o que nos cabe neste início de terceiro milênio é procurar fortalecer o que já foi conquistado como algo fundamental para a construção de nossa identidade cultural.

A grande diversidade, proveniente deste caldeirão cultural é a marca mais importante do país, sendo a integração pela cultura a forma mais eficaz e mais verdadeira de se construir uma nação, pois permite a identificação por algo que ela própria produziu a partir de suas vivências e interações, resultando em suas manifestações culturais. É o que nos diferencia e nos agrega. É o que nos identifica perante o outro. A cultura, não só a erudita, mas 
principalmente a popular, como elemento transformador e agregador de valores, capaz de conscientizar e unir em torno de algo que é verdadeiramente seu.

Hoje, o Estado, através de políticas públicas deve ter como uma de suas premissas, atender às necessidades culturais da população se conscientizando de seu papel fomentador, condutor e integrador cujo objetivo deve ser o desenvolvimento cultural da nação. Suas ações devem focar os valores nacionais e preservar a diversidade cultural possibilitando que as minorias sejam respeitadas e suas expressões culturais divulgadas. Com sua presença como órgão regulador ele pode e deve evitar que a iniciativa privada através das leis de incentivo à cultura direcione seu fomento somente às manifestações culturais de seu interesse ou financie projetos sem garantia de continuidade, corrigindo possíveis desigualdades econômicas e sociais.

O Estado deve ir além da democratização da cultura possibilitando o acesso de todos à toda e qualquer forma de manifestação cultural do país e, principalmente respeitar e incentivar as expressões culturais populares. Deve procurar agir para diminuir a desigualdade na valorização de algumas manifestações em detrimento de outras, procurando atuar de uma forma mais equilibrada no direcionamento de suas políticas públicas para que através da inclusão cultural a cultura passe de sintoma das desigualdades sociais para se tornar o ponto de mudança deste quadro.

Segundo Botelho: "Hoje, parece claro que a democratização cultural não é induzir os

$100 \%$ da população a fazerem determinadas coisas, mas sim oferecer a todos - colocando os meios a disposição a possibilidade de escolher entre gostar ou não de algumas delas (...)" (Botelho, 2001, p.82).

É importante que o governo seja transparente em suas intenções e em suas ações. Devido à grande dimensão territorial do Brasil, é normal a dificuldade em criar 
e integrar uma política cultural que abranja todo o território nacional, talvez realmente seja interessante em alguns aspectos certa regionalização com fomentos diferenciados que consigam atender as peculiaridades de cada região, mas ao mesmo tempo, consiga fazê-las interagir, dialogar, respeitando-se e incentivando-se a diversidade cultural e ao mesmo tempo, procurando integrá- las num contexto mais amplo, articulando-as a partir do governo através de projetos sérios e coerentes.

O último século testemunhou um grande avanço nas diversas áreas de atividade humana e, sem precedentes, na área social em todo o mundo, como no Brasil, sendo que a cultura teve papel fundamental na consolidação do novo ser humano social, mais contestador e participativo. A relação do homem com o testemunho de sua passagem pelo planeta, num cenário tão amplo quanto o universo, encontrou na Museologia o suporte necessário para entender e intensificar essa relação.

Bruno nos diz que um dos problemas enfocados pela Museologia seria justamente: “(...)desenvolver processos para possibilitar que, a partir desta relação, o patrimônio seja transformado em herança e esta, por sua vez, contribua para a necessária construção das identidades". (Bruno, 2001, p.8)

A Nova Museologia nos ampliou o modo de ver esta relação o que possibilitou uma maior interação entre o homem e seu espaço de vida, cabendo ao museu desempenhar o papel de vetor dessa integração entre o homem e o espaço no qual está inserido. O museu ainda está afinando seu discurso procurando acertar o passo de acordo com os novos tempos, com as novas demandas sociais de inclusão, procurando ser mais crítico e participativo, compartilhando com a comunidade na qual está inserido os seus questionamentos. Isto ocorre, pois encontra alguma resistência às mudanças reais que se lhe impõe os novos tempos com suas novas necessidades, resistência muitas 
vezes encontrada em si mesmo.

O medo parece ser o maior desafio a ser enfrentado pelo museu. O medo da mudança, o medo do novo, o medo de perder um status que na realidade não existe mais. 0 mundo mudou, os conceitos mudaram e o momento atual é o do enfrentamento dos desafios que a sociedade lhe coloca: como tornar-se acessível a todos sem perder a sua identidade! Como se abrir sem se descaracterizar! Como partilhar sem perder o foco de sua missão!

Precisamos retirar o que ainda resta de ranço no olhar do museu. Permitir-lhe se abrir inteiramente para as novas necessidades que a sociedade lhe cobra. Para tanto é necessário ir atrás de novos paradigmas. Conceitos como preservar necessitam de uma releitura. Comunicar apenas para glorificar, não permitindo uma identificação com o público também está fadado a perder espaço no novo papel que o museu se propôs a desempenhar. Estamos num momento de enfrentarmos os novos desafios e para isto é necessário reavaliarmos nossos códigos e termos coragem de reestruturá-los, senão corremos o risco de mudanças superficiais que em pouco tempo poderão se tornar obsoletas.

Estes são alguns dos desafios que permeiam os caminhos que já estão sendo trilhados, mas o mais difícil é a mudança de atitude. Esta precisa ser incorporada, cotidianizada nas ações pretendidas e desenvolvidas pelo museu e sua equipe.

Não podemos perder de vista o que foi defendido e corroborado por todos nos vários Encontros, Mesas Redondas e Simpósios promovidos por entidades como o ICOM e a UNESCO no decorrer do último século, com vistas a estabelecer o caráter social da museologia. Mais importante do que pormos no papel a nova ordem museológica, é colocá-la em prática e, para tanto, políticas específicas devem ser priorizadas, porque elas já existem. O poder 
público tem sobre si a obrigação de imprimir diretrizes e possibilitar recursos, principalmente, humanos para darmos prosseguimento à árdua missão de difundir, de sociabilizar a cultura.

O museu não pode modificar a sociedade. Ele pode no máximo modificar a si próprio e, assim, contribuir para a conscientização e modificação da sociedade como um todo fornecendo os instrumentos necessários para o exercício da cidadania responsável que, atuando criticamente ajudará a combater as desigualdades sociais. Retirar as barreiras atitudinais é o primeiro passo decisivo para essa mudança de postura. Não apenas aceitar a presença, mas permitir o total acesso aos códigos que não precisam ser de poucos, podem e devem ser decodificados em uma linguagem transparente para que a arte, a história, a ciência e tudo o mais possam ser contempladas, vivenciadas e pertencidas por muitos.

Baseado no que foi exposto concluímos que o museu precisa assumir de vez a sua responsabilidade como agente de transformação social e seus profissionais se conscientizarem de que são trabalhadores sociais e os principais atores desta mudança. Desenvolver programas inclusivos é um passo importante, mas somente o primeiro, pois a integração do público deve ser total. A sociedade deve ser incentivada a participar e a compartilhar de todo o processo cultural formando juntamente com o museu o alicerce que fortaleça mais e mais a identidade cultural desta nação tão diversa em suas múltiplas faces culturais.

\section{Bibliografia:}

Aidar, G. (2002). Museus e inclusão social. Ciências \& Letras, N. 31 - Porto Alegre , (pp.53-62).

Araújo M. M. \& Bruno, M. C. (1995). Memória do Pensamento Muserológico Contemporâneo.

Documentos e Depoimentos. Comitê Brasileiro do ICOM . 
Barbato Jr., R. (2004). Missionários de uma utopia nacional-popular_os intelectuais e o departamento de cultura de são paulo. São Paulo: AnnaBlume editoracomunicação.

Barros, J. M. (2008). Corrêa, R. M. (org.) Avanços e desafios na construção de uma sociedade inclusiva. Acesso em 12 de 10 de 2010, disponível em Sociedade Inclusiva- PUC Minas: http://www.proex.pucminas.br/sociedadeinclusiva /arquivos/avancosedesafiosnaconstrucaodeumasociedadeincl usiva.pdf\#page $=49$

Botelho, I. (2001). As dimensões da cultura e o lugar das políticas públicas. Acesso em 03 de agosto de 2010, disponível em São Paulo em Perspectiva vol.15 no.2 São Paulo http://www.scielo.br/scielo.php?script=sci_arttext\&pid=S010 2-88392001000200011

Brant, L. (2005). (org.) Diversidade Cultural Globalização e culturas locais: dimensões, efeitos e perspectivas. São Paulo: Escrituras Editora e Instituto Pensarte.

Bruno, C. (2001-2002). Museologia: princípios teóricometodológicos e a historicidade do fenômeno museal. São Paulo: Curso de Especialização em Museologia.

Bruno, C. (1997). Museus hoje para o amanhã. Cadernos de Sóciomuseologia N. 10 , (pp.35- 42). Acesso em 20 de janeiro de 2010, disponível em: http://revistas .ulusofona.pt/index.php/cadernosociomuseologia

Calabre, L. (2007). A ação federal na Cultura: o caso dos conselhos. Acesso em 14 de novembro de 2010, disponível em $\mathrm{O}$ público e o privado - n. 9: http://www.politicasuece.com/v6/admin/publicacao/mapps_ 4_123.pdf

Chiovatto, M. M. (s.d.). Museu, imaginação e formação dos sujeitos: a experiência da Pinacoteca do Estado de SP: Google Docs. Acesso em 22 de 06 de 2010, disponível 
em www.gedest.unesc.net/seilacs/museuexperiencia_mila. pdf

Coelho, T. (2004). Dicionário de Política Cultural. São Paulo: Editora lluminuras Ltda (Original publicado em 1997).

Constança, J. P. M. (1993). A Evolução de conceiros entre as declarações de Santiago e Caracas. Cadernos de Sociomuseologia, n. 1 , (pp. 121-129). Acesso em 20 de janeiro de 2010, disponível em: http://revistas. ulusofona.pt/index.php/cadernosociomuseologia

Gomes, M. F. F. F. O museu como Vetor da Inclusão Cultural. Dissertação de Mestrado. Orientador Prof. Dr. Marcelo Nascimento Bernardo da Cunha. Universidade Lusófona de Humanidades e Tecnologia em 2010.

IBGE- Instituto Brasileiro de Geografia e Estatística Comunicação Social de 16 de setembro de 2005 - disponível em http://www.ibge.gov.br/home/presidencia/noticias/ noticia_impressao.php?id_noticia=438 Acesso em 05/11/ 2010.

ICOM - Comitê Internacional de Museus. Definição de museu aprovada pela 20ạ Assembleia Geral. Barcelona, Espanha, 6 de julho de 2001. In: SBM - Sistema Brasileiro de Museus.

Definições de Museu - Comitê Internacional de Museus. Disponível em: <http://www.museus.gov.br/ oqueemuseu_museusicom.htm>. Acesso em: 10/06/2010. Instituto Português de Museus (IPM). (2004). Museus e Acessibilidade. Coleção Temas de Museologia. Lisboa: Facsimile, Lda. Acesso em 06 de junho de 2010, disponível em: http://www.ipmuseus.pt/pt.PT/recursos/publicacoes /pub_museologia/ContentList.aspx?page $=2$

Moutinho, M. (1993). Sobre o Conceito de Museologia Social. Cadernos de Museologia, v. 1 , (pp. 5-10). Acesso em 20 de janeiro de 2010, disponível em: http://revistas.ulusofona.pt/index.php/cadernosociomuseolo gia 
Primo, J. S. (1999). Pensar contemporaneamente a museologia. Cadernos de Sociomuseologia, n. 16 , (pp. 5-26). Acesso em 20 de janeiro de 2010, disponível em: http://revistas.ulusofona.pt/index.php/cadernosociomuseolo gia

Rubim, A. A., Rubim, I. \&. Vieira, M. P. (2005). Atores sociais, redes e políticas culturais. In: Convênio Andrés Bello. Acesso em 23 de 08 de 2010, disponível em Cátedras para la integración. Bogotá, Convênio Andrés Bello, (pp. 1-52): http://www.cult.ufba.br/arquivos/atoressociais_redes_e_poli ticasculturais_catedra2005.pf

Santos, M. C. (2001). Museu e Educação: conceitos e métodos. Artigo extraído do texto produzido para aula inaugural do Curso de Especialização em Museologia do Museu deArqueologia e Etnologia da USP, proferida na abertura do Simpósio Internacional, (pp. 1- 22). São Paulo.

Silva, F. A. B. (2007). Política Cultural no Brasil, 20022006: acompanhamento e análise.

Coleção Cadernos de Políticas Culturais; v. 2. Brasília: Ministério da Cultura. Acesso em 02 de julho de 2010, disponível em: http://www.ipea.gov.br/sites/000/2/livros/ cardenosdepoliticas/caderno02.pdf

The GLLAM Report (2000). Museums and Social Inclusion. Leicester: University of Leicester.

Tojal, A. P. (2008). Museu e Inclusão Social. Congresso Brasileiro do Trabalho da Pessoa com Deficiência CONDEF, (pp. 1-7). Florianópolis / Santa Catarina.

Tojal, A. P. (2007). Políticas Públicas de Inclusão de Públicos Especiais em Museus. Tese de Doutorado apresentada na Escola de Comunicação e Artes, Universidade de São Paulo, São Paulo. Orientada por Maria Helena Pires Martins. 